\title{
GC-MS Analysis of Active and Applicable Compounds in Methanol Extract of Sweet Star Fruit (Averrhoa carambola L.) Leaves
}

\author{
Ni Putu Adriani Astitii, 2*, Yan Ramona ${ }^{1,3}$ \\ ${ }^{1}$ School of Biology, Faculty of Mathematics and Science, Udayana University, Badung, Bali, Indonesia \\ ${ }^{2}$ Integrated Laboratory of Sciences, Faculty of Mathematics and Sciences, Udayana University, Badung, Bali, Indonesia \\ ${ }^{3}$ Integrated Laboratory of Biosciences and Biotechnology, Udayana University, Badung, Bali, Indonesia
}

ARTICLE INFO

Article history:

Received June 20, 2020

Received in revised form December 20, 2020

Accepted December 24, 2020

\section{KEYWORDS:}

Averrhoa carambola,

active compounds, lawar,

GC-MS analysis

\begin{abstract}
The leaves of star fruit plants (Averrhoa carambola) have been traditionally used to cure many diseases, such as hypertension and fever. Besides, the leaves of this plant have also widely been used as the main raw material in lawar (a Balinese traditional food) making. In this research, the methanol extract of this plant leaves was analyzed and identified for active compound contents. The main objective of this research was to investigate types of possible active and applicable compounds contained in such leaves, previously extracted/macerated in methanol solution. Analysis was conducted by applying GC-MS instrumentation using methanol solution. The results showed that 10 possible active and applicable compounds (Butane, 1,1-diethoxy-3 methyl-(CAS)1.1-DII, Dodecanoic acid, methyk ester(CAS) methyl, Dodecanoic acid, methyl ester (CAS) Ethyl Laun, Pentadecanoic acid ethyl ester, Hexadecanoic acid methyl ester (CAS) Methyl pa, OCTADECA 9.12 DIENOIC ACID METHYL, 9-Octadecenoic acid methyl ester (E)-(CAS), Octadecanoic acid methyl ester, and (E) 9-Octadecanoic acid ethyl ester) were identified in methanol extract of such leaves. Among those compounds, Butane, 1,1-diethoxy-3-methyl and Hexadecanoic acid, methyl ester was two most abundance constituents with percentage of peak areas of $35.67 \%$ and $26.93 \%$, respectively.
\end{abstract}

\section{Introduction}

Sweet star fruits plants are fruiting all seasons for the whole year. The fruits of this plants contain high level of vitamin $A$ and $C$ and have potential as antioxidant properties. Leaves and fruits of this plant have been used emphirically to cure various diseases, such as skin diseases, worm infestations, diarrhea, vomiting, hemorrhoids, or intermittent fever. These were extensively reviewed by Dasgupta et al. (2013) and Muthu et al. (2016). In Bali, such plant leaves have also been used as raw material for lawar (a traditional Balinese food) making. Such traditional food is commonly served in any Balinese ceremonial evets, such as temple festivals or weding ceremony (Astiti et al. 2019).

Herbal medicines developed worldwide have also been conducted by exploiting potential plant components. This indicates that people tend to be back to nature to achieve optimal healthiness or to cope with various diseases naturally. Radical-induced oxidative stress

\footnotetext{
* Corresponding Author

E-mail Address: adriani@unud.ac.id
}

has been recognized to stimulate various degenerative related diseases, such as cancer, coronary heart attack or early aging (Phaniendra et al. 2014). Human body frequently needs additional antioxidant to fulfil the body need, and this can often be obtained from plant materials (Ping Xu et al. 2016). Chau et al. (2004) as reviewed by Saghir et al. (2013) found that insulable fiber-rich fractions of pomace of $A$. corembola effectively increase glucose absorption, retard glucose diffusion, delay the release of glucose from starch, and inhibit the activity of $\alpha$-amylase to different extents. These results in a decreased glucose level in blood of animals used in their experiment. In other words, the compounds of such plant have hypoglycemic effect on the animals.

In our body, metabolic pathways of complex molecules often produce molecules with unpaired electron on their outermost orbit that make them very reactive. These molecules are known as free radicals (Phaniendra et al. 2014). Such molecules tend to initiate chain reactions within human body and cause damages continuously (Butnariu and Samfira 2012). These free radicals have been reported to have adverse effect in many biological complex molecules, such as protein, lipid, as well as 
nucleic acids by altering normal status of redox reaction involving such complex molecules which lead to an increase in oxidative stress (Phaniendra et al. 2014). Under normal conditions, human body has endogenic defence system against these free radicals. This is normally overcome by cellular metabolism of normal cells and inflammation (Closa and Folch-Puy 2004). The level of free radical species in human body is also reported to be due to stress factors, such as radiation, smoke of cigarette, and pollution (Srivastava and Kumar 2014). If this happens, our body will need extra antioxidant that can be obtained from our diets to neutralize those excessive free radicals.

Being a mega biodiversity country, Indonesia has various types of plants with high antioxidant content. Star fruit plants are examples of Indonesian flora that need to be explored as antioxidant sources. The leaves of those plants (in the form of foods, such as lawar) are believed to improve human health by Balinese people (Yusa and Suter 2014; Astiti et al. 2019), although knowledge on pharmacological potency of such leaves is still limited until recently. Therefore, identification of active and applicable compounds content of such plant leaves is urgently needed, and this was conducted in our current research. The main objective of this research was to investigate types of active compounds contained in the extract of leaves of such plants, so that their potency for health improvement and other applications can be recognized.

\section{Materials and Methods}

This is an explorative research using methanol extract of sweet star fruit leaf powder. Extraction was conducted by maceration method specified by Fauziati(2017). A quantity of 50 g leaf powder of sweet star fruit plant (A. carambola) was extracted with 250 $\mathrm{ml}$ methanol, shaken for 2 hours, macerated for 24 hours, and filtered. The filtrate was then evaporated in a vacuum rotary evaporator at $50^{\circ} \mathrm{C}$ to concentrate the extract, and fractionated through a silica gel column using eluents with various polarities. The choice of eluent was based on like dissolves like. The moving phase eluents used were: $100 \% n$-hexane, $n$-hexane: dichloromethane $(1: 1), 100 \%$ dichloromethane, dichloromethane:ethyl acetate (1:1), 100\% ethyl acetate, ethyl acetate:ethanol; (1:1), 100\% ethanol, ethanol:methanol (1:1), and $100 \%$ methanol. The amount of each eluent used was $50 \mathrm{ml}$. The active components of the extract of sweet star fruit plant leaves was analysed using a GC MS instrumentation (GC-MS QP-2010 Ultra Shimadzu equipped with GCMS postrun analysis and GC-MS real time analysis software). The conditions of the GC instrument were adjusted as specified in Solanki et al. (2018) with slight modification. The injection port temperature was maintained at $270^{\circ} \mathrm{C}$ and the setting of column temperature was from $50^{\circ} \mathrm{C}$ to $220^{\circ} \mathrm{C}$ and then increased to $270^{\circ} \mathrm{C}\left(10^{\circ} \mathrm{C} /\right.$ minute $)$, ending with 10 minutes constant temperature of $270^{\circ} \mathrm{C}$. Helium UHP gas (ALPHAGAZ He Helium) was used as the carrier. The identification of the appeared constituents was conducted by matching them with those specified either in the Willey7.Libraries database or NIST08.LIB database.

\section{Results}

Table 1 and figures $1-10$ show possible active and applicable compounds or constituents contained in the methanol extract of sweet star fruit leaves. In our research, ten main compounds appeared following GC-MS analysis. As shown in Table 1, Butane, 1,1-diethoxy-3-methyl and Hexadecanoic acid, methyl ester appeared to be two most abundance compounds successfully extracted from leaves of Averrhoa carambola with percentage peak areas of $35.67 \%$ and $26.93 \%$, respectively. The other 8 compounds produced percentage of peak areas in the range of $1.52-10.99 \%$ (Table 1 ).

Table 1. Compounds with various retention times, percentages of peak areas, molecular formula, and molecular weight appeared following GC-MS analysis

\begin{tabular}{lcccc}
\hline Name & $\mathrm{RT}^{*}$ (Minutes) & Peak area ( \% ) & Molecular formula & Molecular weight \\
\hline Butane, 1,1-diethoxy-3-methyl & 3,594 & 35.67 & $\mathrm{C}_{9} \mathrm{H}_{20} \mathrm{O}_{2}$ & 160 \\
Dodecanoic acid, methyl ester & 11,697 & 3.62 & $\mathrm{C}_{13} \mathrm{H}_{26} \mathrm{O}_{2}$ & 214 \\
Dodecanoic acid ethyl ester & 12,551 & 5.15 & $\mathrm{C}_{14} \mathrm{H}_{28} \mathrm{O}_{2}$ & 228 \\
Pentadecanoic acid, ethyl ester & 14,824 & 2.47 & $\mathrm{C}_{17} \mathrm{H}_{34} \mathrm{O}_{2}$ & 270 \\
Hexadecanoic acid, methyl ester & 16,215 & 26.93 & $\mathrm{C}_{17} \mathrm{H}_{34} \mathrm{O}_{2}$ & 270 \\
Hexadecanoic acid, ethyl ester & 16,890 & 8.69 & $\mathrm{C}_{18} \mathrm{H}_{36} \mathrm{O}_{2}$ & 284 \\
Octadeca-9,12-dienoic acid methyl & 17,868 & 1.52 & $\mathrm{C}_{19} \mathrm{H}_{34} \mathrm{O}_{2}$ & 294 \\
9-Octadecenoic acid, methyl ester & 17,933 & 10.99 & $\mathrm{C}_{19} \mathrm{H}_{36} \mathrm{O}_{2}$ & 296 \\
Octadecanoic acid, methyl ester & 18.165 & 2.31 & $\mathrm{C}_{19} \mathrm{H}_{38} \mathrm{O}_{2}$ & 298 \\
9-Octadecenoic acid ethyl ester & 18.545 & 2.67 & $\mathrm{C}_{20} \mathrm{H}_{38} \mathrm{O}_{2}$ & 310 \\
\hline
\end{tabular}

*Retention time 
$\ll$ Target $\gg$

Line\#:1 RTime:3.595(Scan\#:120) MassPeaks:292

RawMode:Averaged 3.590-3.600(119-121) BasePeak:102.95(3490538)

BG Mode:Calc from Peak Group 1 - Event 1

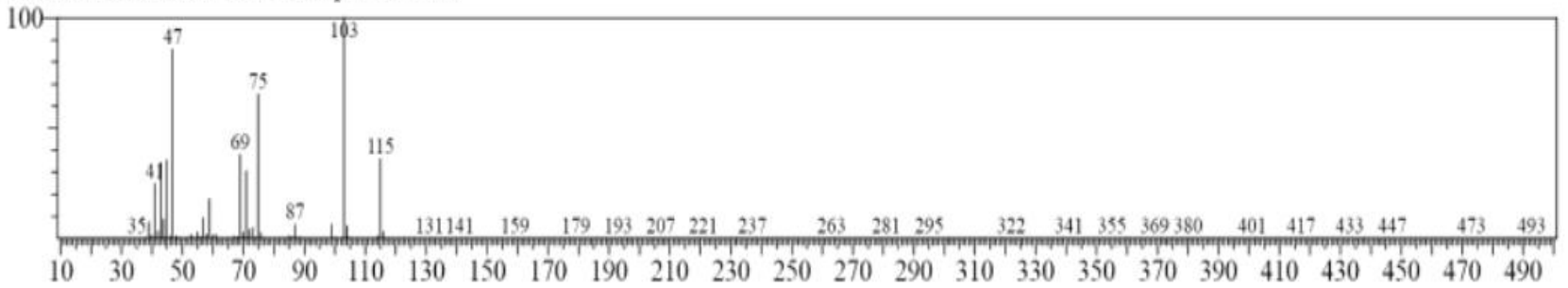

Hit:1 Entry:49541 Library:WILEY7.LIB

SI:93 Formula:C9 H20 O2 CAS:3842-03-3 MolWeight:160 RetIndex:0

CompName:Butane, 1,1-diethoxy-3-methyl- (CAS) 1,1-DIETHOXYISOPENTANE \$\$ 1,1-Diethoxy-3-methylbutane \$\$ Isovaleraldehyde diethyl acetal S\$ ]

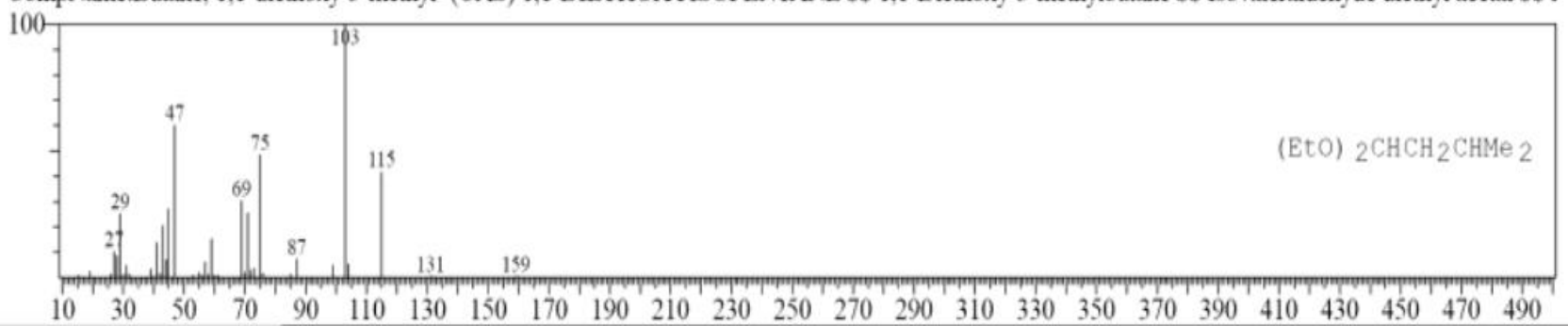

Figure 1. The GC-MS mass spectra of Butane,1,1-diethoxy-3-methyl

$\ll$ Target $\gg$

Line\#:2 R.Time:11.695(Scan $\#: 1740$ ) MassPeaks:284

RawMode:Averaged 11.690-11.700(1739-1741) BasePeak:73.90(469773)

BG Mode:Calc. from Peak Group 1 - Event 1

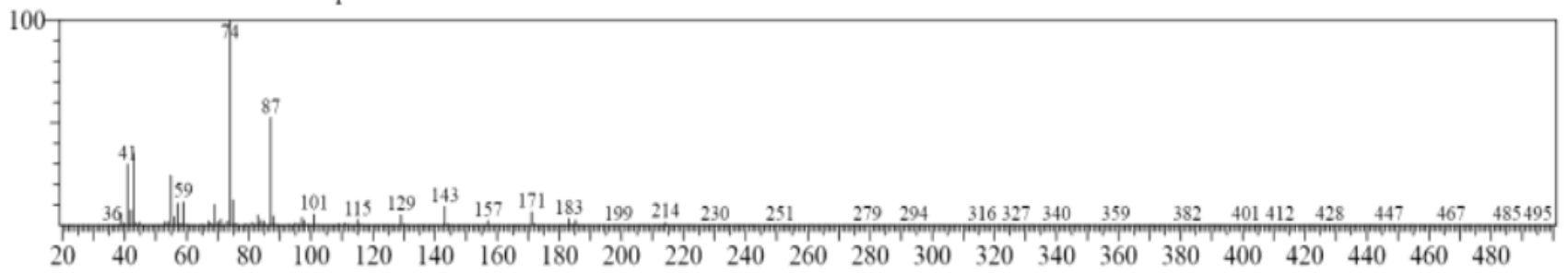

Hit:1 Entry:113510 Library:WILEY7.LIB

SI:97 Formula:C13 H26 O2 CAS:111-82-0 MolWeight:214 RetIndex:0

CompName:Dodecanoic acid, methyl ester (CAS) Methyl laurate \$S Methyl dodecanoate SS Methyl n-dodecanoate \$S Lauric acid methyl ester S\$ Metholen

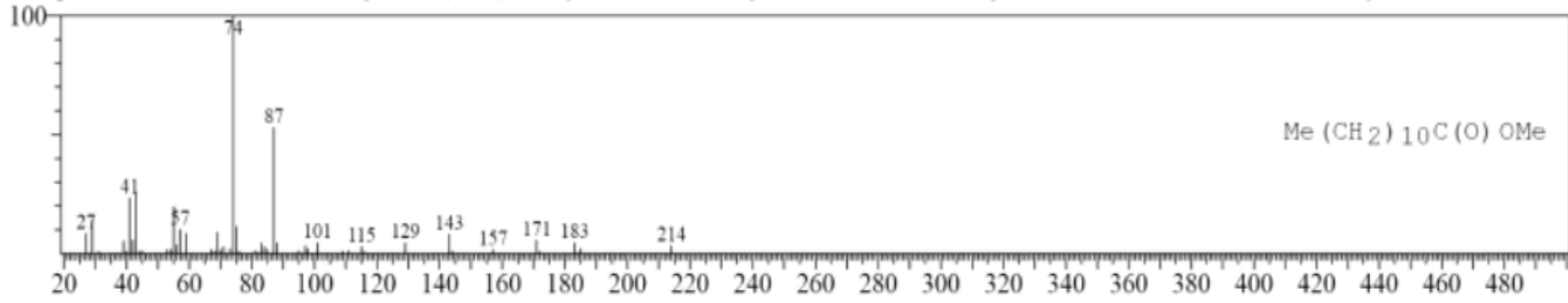

Figure 2. The GC-MS mass spectra of Dodecanoic acid, methyl ester 
$<<$ Target $\gg>$

Line\#:3 R Time:12.550(Scan\#:1911) MassPeaks:299

RawMode:Averaged 12.545-12.555(1910-1912) BasePeak:87.95(750583)

BG Mode:Calc. from Peak Group 1 - Event 1

100

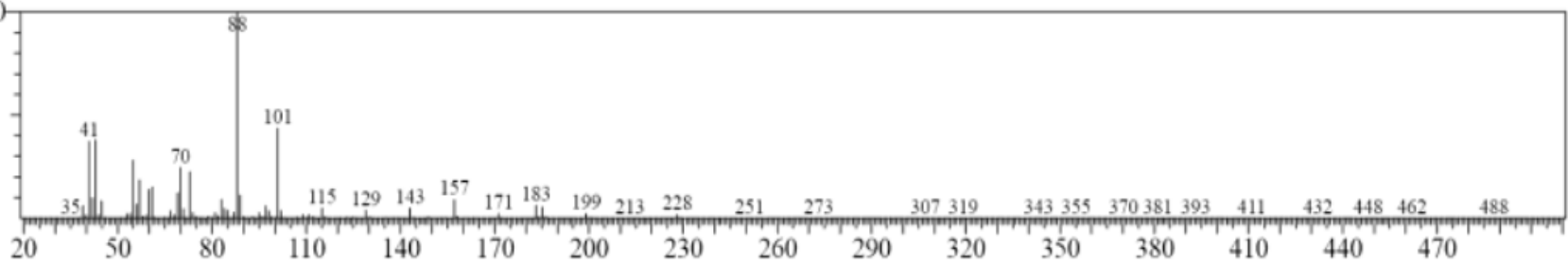

Hit\#:1 Entry:131472 Library:WILEY7.LIB

SI:96 Formula:C14 H28 O2 CAS:106-33-2 MolWeight:228 RetIndex:0

CompName:Dodecanoic acid, ethyl ester (CAS) Ethyl laurate S\$ Ethyl dodecanoate SS Ethyl laurinate \$S Ethyl dodecylate S\$ Lauric acid, ethyl ester S\$

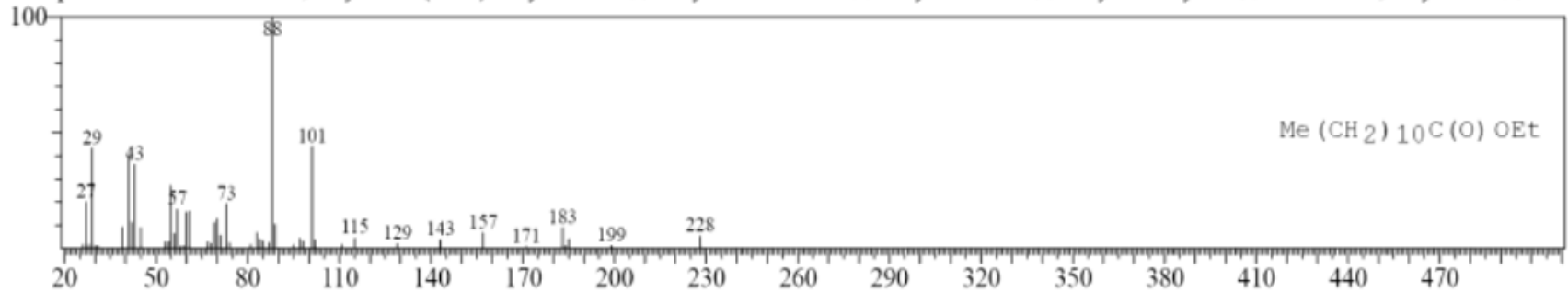

Figure 3. The GC-MS mass spectra of Dodecanoic acid ethyl ester

Hit\#: 1 Entry: 180467 Library:WILEY7.LIB

SI:96 Formula:C17 H34 O2 CAS:41114-00-5 MolWeight:270 RetIndex:0

CompName:Pentadecanoic acid, ethyl ester SS ethyl pentadecanoate SS n-Pentadecanoic acid ethyl ester SS

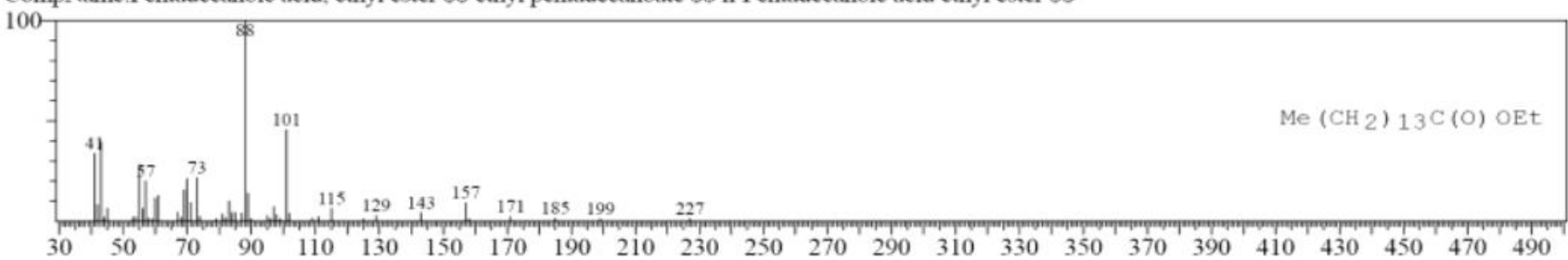

$\ll$ Target $\gg$

Line $\#: 4$ R. Time: 14.825 (Scan $\#: 2366$ ) MassPeaks:308

RawMode:Averaged 14.820-14.830(2365-2367) BasePeak:87.95(356457)

BG Mode:Calc. from Peak Group 1 - Event 1

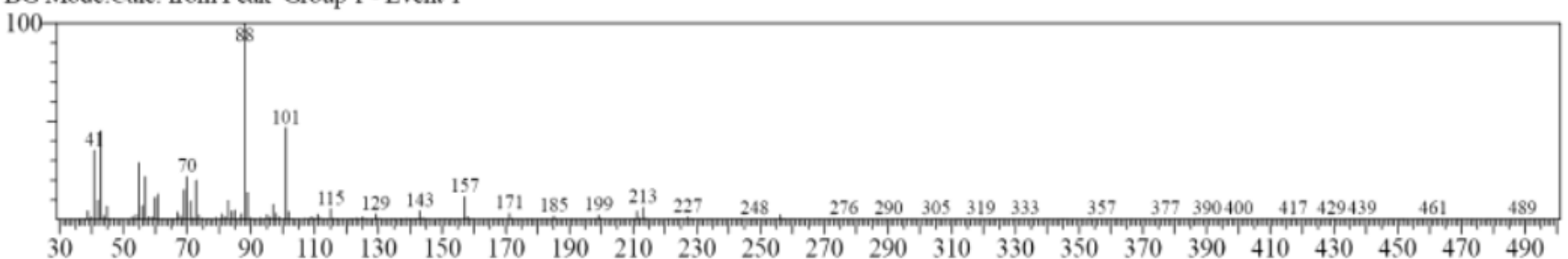

Figure 4. The GC-MS mass spectra of Pentadecanoic acid, ethyl ester 
$\ll$ Target $\gg$

Line $: 5$ R. Time: 16.215 (Scan\#:2644) MassPeaks:347

RawMode:Averaged 16.210-16.220(2643-2645) BasePeak:73.90(4124953)

BG Mode:Calc. from Peak Group 1 - Event 1

100

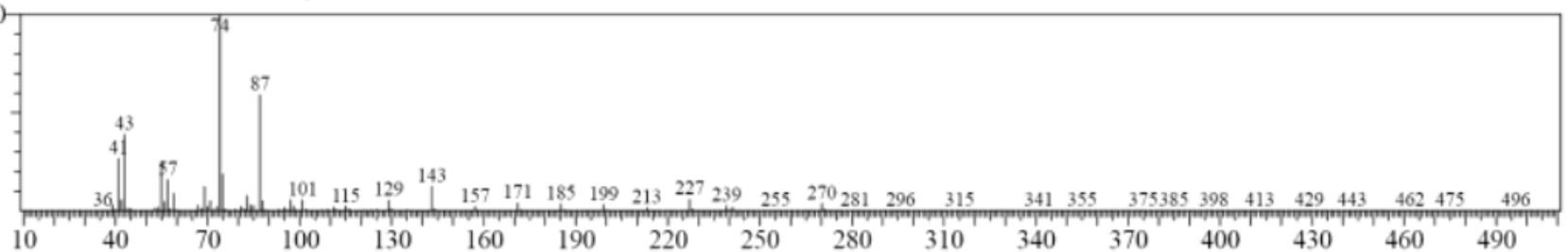

Hit :1 Entry:180433 Library:WILEY7.LIB

SI:98 Formula:C17 H34 O2 CAS:112-39-0 MolWeight:270 RetIndex:0

CompName:Hexadecanoic acid, methyl ester (CAS) Methyl palmitate \$S Methyl hexadecanoate \$\$ Methyl n-hexadecanoate \$\$ Uniphat A60 \$\$ Metholene :

100

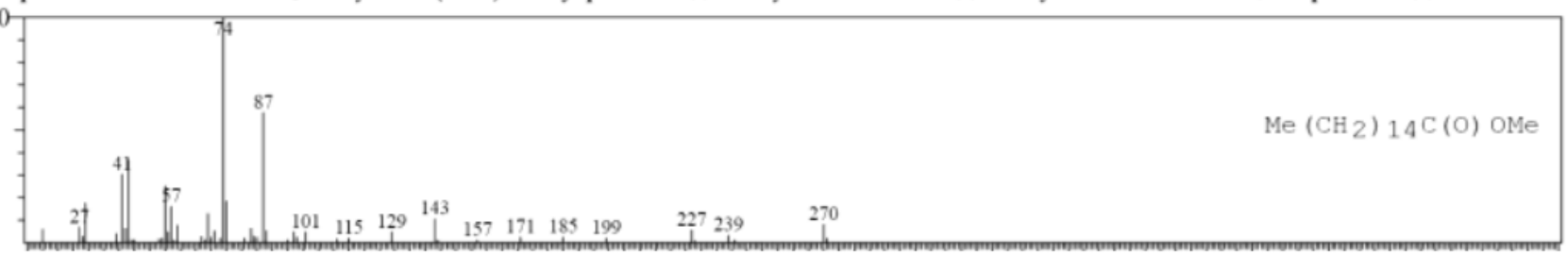

Figure 5. The GC-MS mass spectra of Hexadecanoic acid, methyl ester

$<$ Target $\gg>$

Line\#:6 R.Time:16.890(Scan\#:2779) MassPeaks:315

RawMode:Averaged 16.885-16.895(2778-2780) BasePeak:87.95(1270956)

BG Mode:Calc. from Peak Group 1 - Event 1

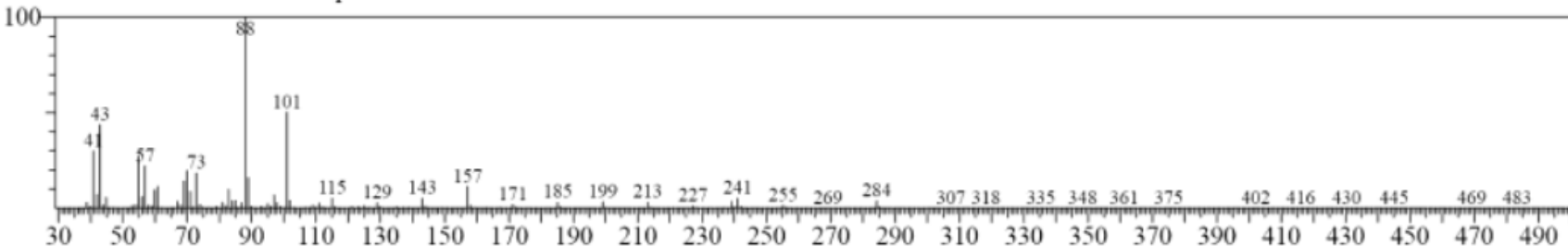

Hit\#:1 Entry:195615 Library:WILEY7.LIB

SI:96 Formula:C18 H36 O2 CAS:628-97-7 MolWeight:284 RetIndex:0

CompName:Hexadecanoic acid, ethyl ester (CAS) Ethyl palmitate S\$ HEXADECANOIC ACID ETHYL ESTER S\$ Palmitic acid ethyl ester S\$ Palmitic aci 100

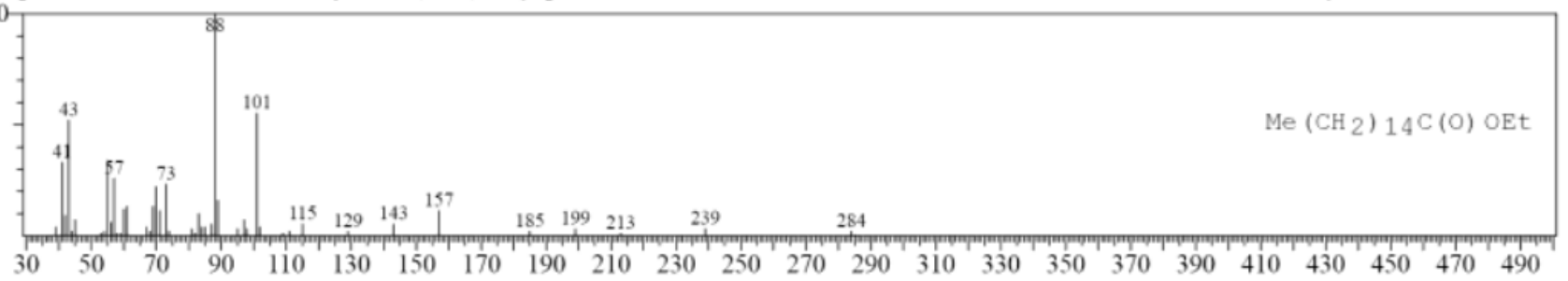

Figure 6. The GC-MS mass spectra of Hexadecanoic acid, ethyl ester 
$<$ Target $>>$

Line $\#$ :7 R.Time: $17.870($ Scan\#:2975) MassPeaks:294

RawMode:Averaged 17.865-17.875(2974-2976) BasePeak:66.90(205563)

BG Mode:Calc. from Peak Group 1 - Event 1

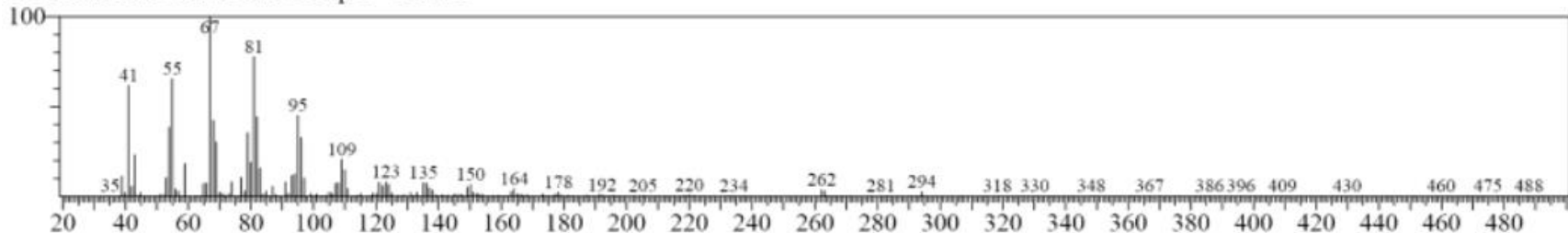

Hit\#:1 Entry:205831 Library:WILEY7.LIB

SI:95 Formula:C19 H34 O2 CAS:2462-85-3 MolWeight:294 RetIndex:0

CompName:OCTADECA-9.12-DIENOIC ACID METHYL ESTER \$\$ 9.12-OCTADECADIENOIC ACID. METHYL ESTER SS

$100-$

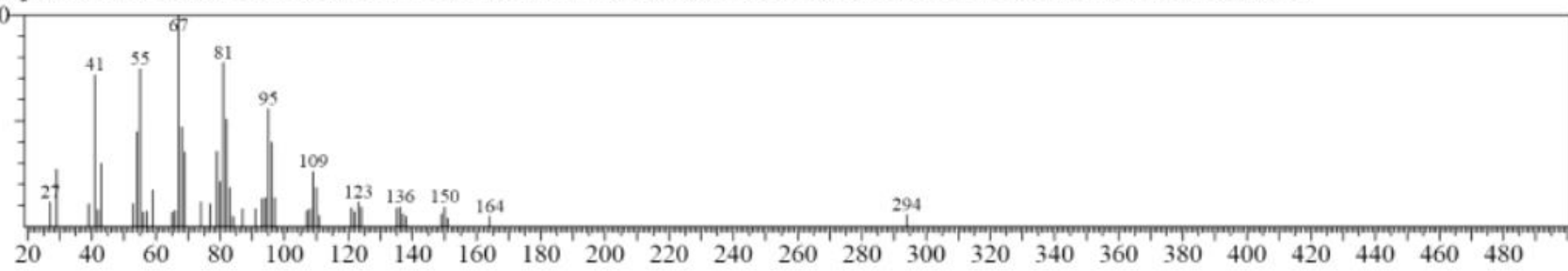

Figure 7. The GC-MS mass spectra of Octadeca-9, 12-dienoic acid methyl ester

$\ll$ Target $\gg$

Line\#:8 R.Time: 17.935 (Scan\#:2988) MassPeaks:360

RawMode:Averaged 17.930-17.940(2987-2989) BasePeak:54.90(1558860)

BG Mode:Calc. from Peak Group 1 - Event 1

100

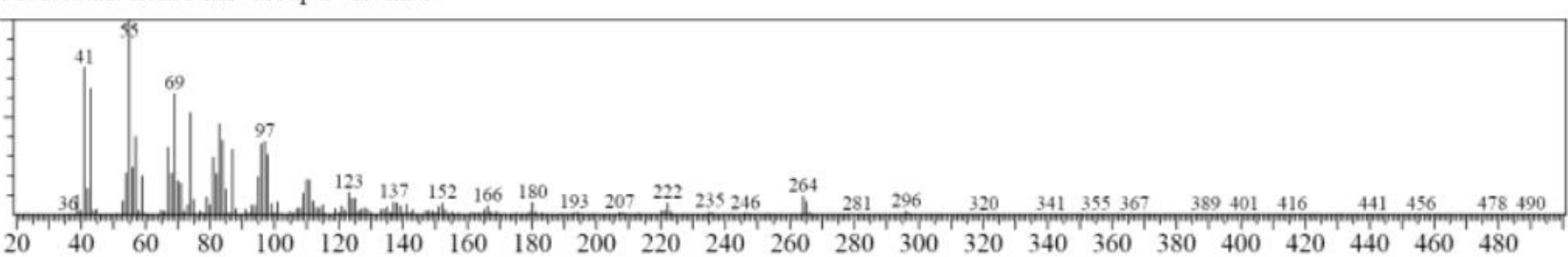

Hit 1 Entry:207872 Library:WILEY7.LIB

SI:96 Formula:C19 H36 O2 CAS:1937-62-8 MolWeight:296 RetIndex-0

CompName:9-Octadecenoic acid, methyl ester, (E)- (CAS) Methyl elaidate SS METHYL-TRANS 9-OCTADECENOATE SS Elaidic acid methyl ester S\$ El $100-$

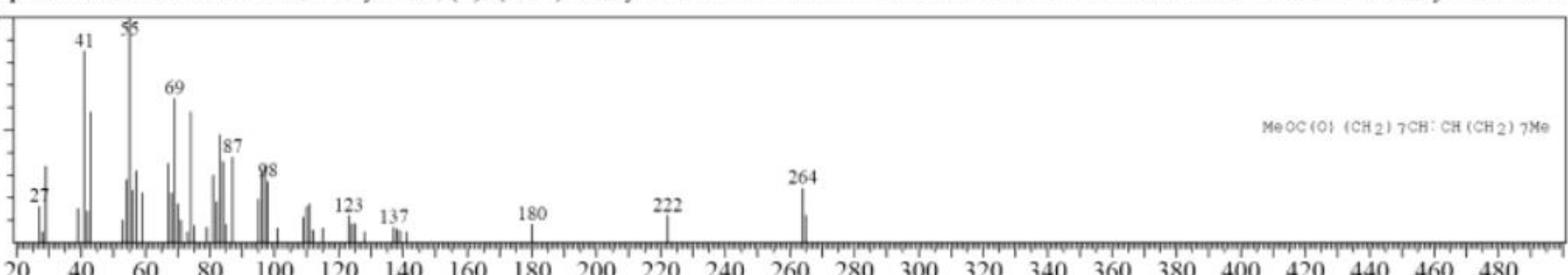

Figure 8. The GC-MS mass spectra of 9-Octadecenoic acid, methyl ester 
$<$ Target $>$

Linet 9 R. Time:18.165(Scan+3034) MassPeaks:318

RawMode:Aweraged 18.160-18.170(3033-3035) BasePeak:73.90(315873)

BG Mode:Calc. from Peak Group 1 - Event 1

100

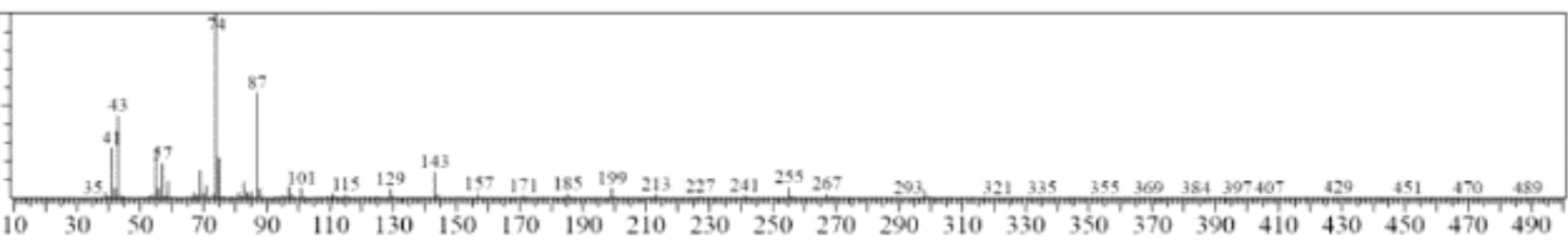

Hitt:1 Entry:24246 Library:NIST08s. LB

SI:97 Formula:C19H3802 CAS:112-61-8 MolWeight:298 Retlndex:2077

CompName:Octadecanoic acid. methyl ester SS Stearic acid. methyl ester \$S n-Octadecanoic acid. methyl ester \$S Kemester 9718 SS Methyl n-octadecanoat 100

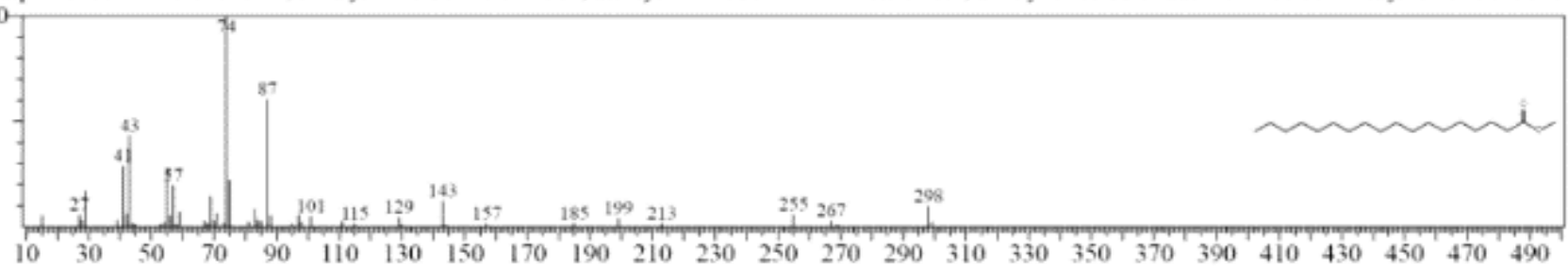

Figure 9. The GC-MS mass spectra of Octadecanoic acid, methyl ester

Target

Line $: 10$ R.Time: 18.545 (Scan $: 3110)$ MassPeaks:349

RawMode:Averaged 18.540-18.550(3109-3111) BasePeak:5490(378548)

BG Mode Calc from Peak Group 1 - Event 1

100

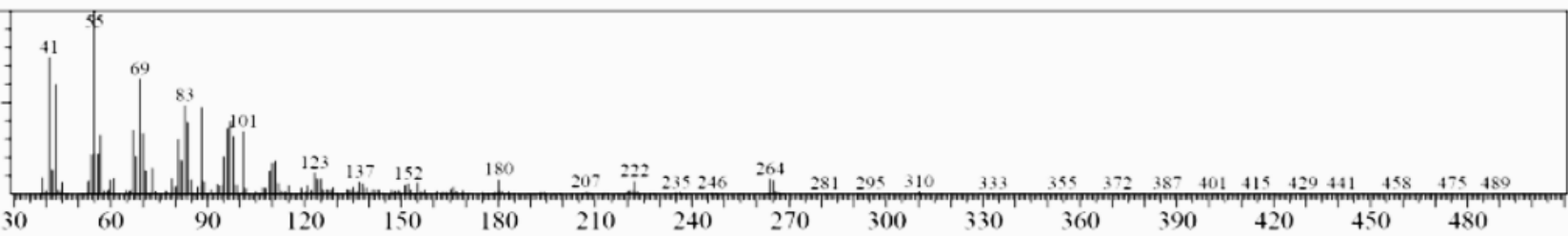

Hit + I Entry: 119255 Library:NIST08 LIB

SI95 Formula C20H38O2 CAS 6114-18-7 MolWeight 310 RetIndex 2185

CompName (E)-9-Octadecenoic acid ethyl ester \$\$ 9-Octadecenoic acid ethyl ester. (E)- \$S Ethyl 9-octadecenoate, (E)- \$\$ Ethyl (9E)-9-octadecenoate \# \$S 100

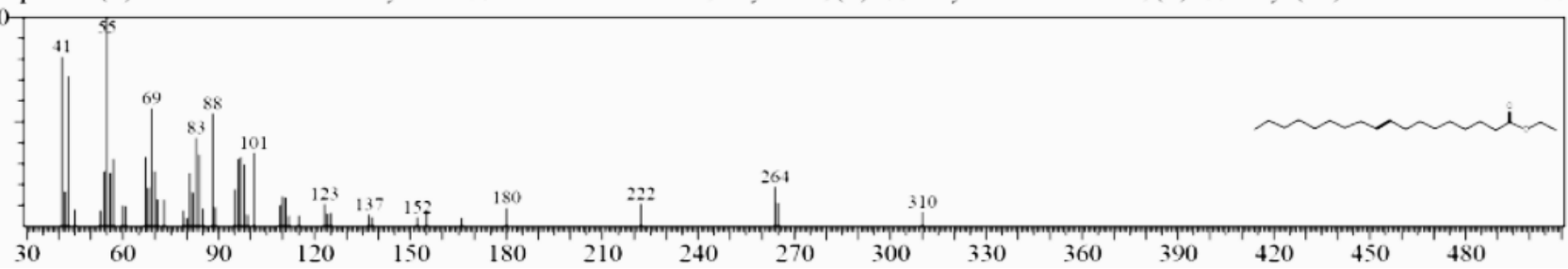

Figure 10. The GC-MS mass spectra of 9-Octadecenoic acid ethyl ester 


\section{Discussion}

\subsection{Butane,1,1-diethoxy-3-methyl}

The peak of this compound has retention time of 3,594 minutes which is identical with Butane, 1,1-diethoxy-3-methyl as specified in the WILEY7. LIB database GC-MS mass spectra. The GC-MS mass spectra of this compound are shown in Figure 1. According to Jong (2015) this compound can be used to synthesize organics, production of ethylene, fuel, mix of petroleum, and raw material for ethylene and butadiene as well as main raw material of synthetic rubber. The same compound was also reported to appear in the tissue cultured plant extract of Stevia rebudiana by Solanki et al. (2018). When compared to the report of Solanki et al. (2018), the retention time of such compound in our research was almost a half. This was probably due to different solvent used in the extraction and GC-MS conditions applied. This appeared to be the most abundance constituent, when compared to other 9 constituents of the methanol extract of Averrhoa carambola with a relative percentage peak area of $35.76 \%$ (Table 1). When compared to the results reported by Solanki et al. (2018) who identified 86 constituents from Stevia rebudiana, this compound is much abundance in Averrhoa carambola. This indicates that leaves of Averrhoa carambola have potential as a source of Butane,1,1-diethoxy-3-methyl.

\subsection{Dodecanoic Acid, Methyl Ester}

The peak of this compound has retention time of 11,697 minutes which is identical to the GC-MS mass spectra of Dodecanoic acid, methyl ester as specified in the WILEY7.LIB database. The retention time of this compound in our result was shorter than that reported by Belakhdar et al. (2015) who found the retention time of such compound of 15.25 minutes. The nature of this compound is fatty acid methyl ester, and it has been reported to have antibacterial, antifungal, and antiviral properties by Özçelik et al. (2005) and Chandrasekaran et al. (2008). Such compound has also been used as an alternative food flavour enhancer (Alibaba 2019). Figure 2 shows the GC-MS mass spectra of the Dodecanoic acid, methyl ester. This constituent occurred in minor concentration in our extract which was indicated by low relative percentage of peak area (3.62\%) (Table 1) when compared to other constituents. Such constituent was also indicated at low level in the extract of Thesium humile by Belakhdar et al. (2015) where its relative percentage of peak area was only $0.09 \%$ among 20 constituents. The GC-MC mass spectra of our extract are shown in Figure 2.

\subsection{Dodecanoic Acid Ethyl Ester}

Dodecanoic acid ethyl ester obtained in our experiment has retention time of 12.55 minutes which is identical to the GC-MS mass spectra specified in WILEY7.LIB database. This is a saturated fatty acid with other names of Ethyl laurate; Lauric acid; Ethyl ester; or Ethyl dodecanoate (Gideon 2015). The mass spectra of this compound are shown in Figure 3. Fatty acids with 14-18 carbon atoms (including this compound) are good raw materials for hard soap making as they will produce foamy soap with high detergency (Cavitch 2001). This compound is also a constituent of essential oils. According to Gideon (2015), dodecanoic acid ethyl ester has potential as antibacterial, antiviral, antioxidant, candidicide, and hypercholesterolemic agents.

\subsection{Pentadecanoic Acid, Ethyl Ester}

The peak produced in GC-MS mass spectra of our extract has retention time of 14,824 minutes which is identical to the GC-MS mass spectra of Pentadecanoic acid, ethyl ester according to WILEY7.LIB database. This compound is a saturated fatty acid belongs to fatty acid ethyl ester (Agoramoorthy et al. 2007). Most saturated fatty acids have been reported to have antifungal and anti-bacterial activity. Figure 4 shows the mass spectra of Pentadecanoic acid, ethyl ester. Pentadecanoic acid, ethyl ester was found to be minor level in our extract with percentage of peak area of $2.47 \%$. Such compound did not exist in Thesium humile extract of Belakhdar et al. (2015). Due to its antifungal and antibacterial properties, it may have many applications in pharmaceutical sectors, although its existence at low concentration in our extract.

\subsection{Hexadecanoic Acid, Methyl Ester}

The peak of this compound has retention time of 16,890 minutes which is identical to the GC-MS mass spectra of Hexadecanoic acid, methyl ester as specified in the WILEY7.LIB database. Hexadecanoic acid methyl ester (metil palmitate) belongs to fatty acid group with capacity as anti-bacteria by disrupting bacterial cell wall and cell membrane. Hexadecanoic acid, methyl ester was the second most 
abundance constituent in our extract with relative percentage peak area of $26.93 \%$. Such compound was also reported by Balakhdar et al. (2015) being one of the most abundance compound in the extract of Thesium humile with relative percentage of peak area of $21.25 \%$ and appeared at retention time of 20.92 minutes. The difference of retention times was probably due to different operational conditions of GC-MS. In the contrary, Hexadecanoic acid, methyl ester did not appear in the ethanol extract of Pistia stratiotes L. and Eichhornia crassipes (Mart.) (Tyagi and Agarwal 2017) and in ethanol extract of Pseudoglochidion anamalayanum (Gideon et al. 2015). Hema et al. (2011) found this compound as an excellent antioxidant and anti-inflammatory constituent. In more recent study Kavitha and Uduman Mohideen (2017) reported that this compound has capacity as antioxidant, hypocholesterolemic, and antiandrogenic. Antimicrobial activity, particularly on fungi, of compounds belong to fatty acid methyl ester (including Hexadecanoic acid, methyl ester) was also reported by Pinto et al. (2016). The ability of this compound to work synergically with various active compounds and increase its anti-bacterial activity was reported by Padmini et al. (2010). The mass spectra of this compound are shown in Figure 5.

\subsection{Hexadecanoic Acid, Ethyl Ester}

This compound has other name of stearic acid which is commonly used as food supplement, cosmetics, and industrial products. In the stearic acid industry, this compound is used as a material in wax, plastic, and soap making in addition to soften rubber. Stearic acid is also used to harden soap. Excessive use of stearic acid causing the soaps less foamy while deficient in stearic acid in soap making will cause the soaps stay liquid (Hart et al. 2003). This compound has been reported to have activities as hypercholesterolemic, lubricant, antimicrobial, flavor, cosmetic, as well as perfumery (Gideon 2015). In more recent study, antitumor activity of this compound was also mentioned in the report of Tyagi and Agarwal (2017). The GC-MC mass spectra of this compound are shown in Figure 6.

\subsection{Octadeca-9, 12-dienoic Acid Methyl}

The peak of this compound has retention time of 17,868 minutes which is identical to the GC-MS mass spectra of Octadeca-9, 12-dienoic acid methyl specified in the WILEY7.LIB database. Other name of this compound is sterculic acid. Plant-based oil consists of sterculic acid with molecular formula of $\mathrm{C}_{19} \mathrm{H}_{34} \mathrm{O}_{2}$. This compound is used in various industries, such as cosmetics, soaps, shampoos, fabric softeners, paints, dan plastics. In kepoh plant, sterculic acid is also used as adaptive biodiesel (Duengo 2011). Figure 7 shows the GC-MS mass spectra of Octadeca-9, 12-dienoic acid methyl. Many species of plants contain such compound with various degree of concentration, dependent on methods used in the extraction. Satheesh Naik et al. (2018) also reported from their study that the methanol extract of Eclipta Alba roots showed the existence of this compound following GC-MS analysis. The peak of this compound appeared at the retention time of 17.9 minutes which is approximately the same as that reported in our current report. In more recent study Starlin et al. (2019) reported 14 compounds from ethanol extract of Tylophora pauciflora, and one of those compounds was identified as Octadeca-9, 12-dienoic acid methyl. They found that the retention time of this compound in the ethanol extract was 16.43 minutes which is similar to our finding as shown in Table 1. The existence of this compound was very minor in our extract with relative percentage of peak area of less than $2 \%$ (Table 1 ). This was significantly lower than that reported by Starlin et al. (2019) where its relative percentage peak area reached $7.93 \%$, among 14 constituents appeared in their extract (ethanol extract of Tylophora pauciflora) following GC-MS analysis.

\subsection{9-Octadecenoic Acid, Methyl Ester}

The GC-MS mass spectra of our extract with retention time of 17,933 minutes (Table 1 ) is identical to mass spectra of 9-Octadecenoic acid, methyl ester based on WILEY7.LIB database. This compound belongs to unsaturated fatty acid methyl ester, with other name of oleic acid (Belakhdar et al. 2015). The mass spectra of this compound are shown in Figure 8. Gideon (2015) also identified this compound in the extract of Pseudoglochidion anamalayanum following GC-MS analysis. The existence of this compound in our extract was relatively high with relative percentage of peak area of $10.99 \%$ (Table 1 ). This value is almost 5 and 6 times higher than that reported by Belakhdar et al. (2015) and Gideon et al. (2015), respectively. The difference of percentage peak areas may be due to different types of plant species extracted. The 9-Octadecenoic acid, methyl ester is the most 
important saturated fatty acid in the production of biodiesel. Biodiesel with high saturated bond has high octant number and resistant to antioxidant. This compound can be used to produce good quality biodiesel (Gultom 2001). Besides, this compound has also potential for use as a flavoring, cancer preventive, as well as an anti-inflammatory agent (Gideon 2015).

\subsection{Octadecanoic Acid, Methyl Ester}

The peak has retention time of 18.165 minutes which is identical to GC-MS mass spectra of $\mathrm{N}$ Octadecanoic acid, methyl ester according to NIST 08.LIB database. This compound belongs to fatty acid methyl ester with a molecular weight of 298 Dalton (Table 1). Although it was not elucidated in our research, some researchers, such as (Imaniar et al. 2013; Perumalsamy et al. 2015) reported that this compound plays important role as insecticide as well as being effective to control larvae of Aedes aegyptii and Culex pipiens pallens. This compound was also found to be effective to control bacterial and fungal growth (Özçelik et al. 2005; Sanchez et al. 2014). Based on the percentage peak area produced, this compound was one of minor compounds in the methanol extract of Averrhoa carambola with a relative peak area of $2.31 \%$ (Table 1). This result was in line with those reported by Belakhdar et al. (2015) who also found such compound as a minor constituent in the extract of Thesium humile, with a relative percentage peak area of $3.07 \%$. The GC-MS spectra of this compound are shown in Figure 9.

\subsection{9-Octadecenoic Acid Ethyl Ester}

The peak of compound with retention time of 18.545 minutes in our extract is identical to GCMS mass spectra of 9-Octadecenoic acid ethyl ester according to NIST 08.LIB database. This is a steroidlike compound which is useful for lubricant and plasticizer (Fessenden and Fessenden 2000). This compound also has perfumery properties (Ross 2003). This compound has several different name, such as Ethyl 9-octadecenoate and Ethyl (9E)-9octadecenoate (Gideon 2015). Such compound also appeared in the extract of Pseudoglochidion anamalayanum (Gideon 2015), Pistia stratiotes L. and Eichhornia crassipes (Mart.) solms (Tyagi and Agarwal 2017), as well as Cenchrus ciliaris L. (Arora et al. 2017). The existence of this compound in our extract was at low level (relative peak area of less than $3 \%$, which is a half of that reported by Gideon (2015). In the contrary, Kanimozhi and Bai (2012) reported that 9-Octadecenoic acid ethyl ester is the most abundance constituent in the ethanol extract of Coriandrum sativum with relative percentage of peak area of $56.68 \%$. Although it is only a minor compound in many plant extracts, its importance for industrial use is very significant, particularly as an important constituent of perfumes (Ross 2003). The GC-MS mass spectra of this compound are shown in Figure 10.

\section{Conclusion}

Ten compounds possibly active or applicable in pharmaceutical and other sectors were identified in the methanol extract of sweet star fruit leaves following application of GC-MS instrumentation in the analysis. These include: Butane, 1,1-diethoxy-3 methyl-(CAS)1.1-DII; Dodecanoic acid, methyk ester (CAS) methyl; Dodecanoic acid, methyk ester (CAS) Ethyl Laun; Pentadecanoic acid ethyl ester; Hexadecanoic acid methyl ester (CAS) Methyl pa; Hexadecanoic acid, ethyl ester; Octadeca 9.12 dienoic acid methyl; 9-Octadecenoic acid methyl ester (E)-(CAS); Octadecanoic acid methyl Ester; and 9-Octadecanoic acid ethyl ester. The Butane, 1,1-diethoxy-3-methyl and Hexadecanoic acid, methyl ester appeared to be two most abundance constituents in the methanol extract of Averrhoa carambola, with percentage of peak areas of $35.67 \%$ and $26.93 \%$, respectively.

\section{Acknowledgements}

The Authors would like to acknowledge the Directorate Research and Community Service (DP2M), Directorate of Higher Education through Higher Education Primary Research (PDUPT) for their financial support on this research. Our thanks should also go to the head of Biochemistry Laboratory, School of Biology as well as the head Integrated Laboratory for Science, Faculty of Mathematics and Science for laboratory facilities provided during this research. 


\section{References}

Alibaba. 2019. Metil Laurate. Available at: https://indonesian. alibaba.com/product-detail/methyl-lauratec13h26o2-447945678.html [Date accessed: 28 Mei 2019]

Arora $S$ et al. 2017. Screening and evaluation of Bioactive components of Cenchrus ciliaris L. by GC-MS analysis. International Research Journal of Pharmacy 8:69-76. DOI:10.7897/2230-8407.08699

Agoramoorthy G et al. 2007. Antibacterial and antifungal activities of fatty acid methyl esters of the blindyour-eye mangrove from India. Brazilian Journal of Microbiology 38:739-742.

Astiti NPA et al. 2019. Analysisi of phenolic and tannin contents in the methanol extract of sweet and sour star fruit plant (Averrhoa carambola $\mathrm{L}$ ) leaves commonly used as raw materials of lawar (a Balinese traditional food). Journal of Advances in Tropical Biodiversity and Environmental Sciences 3:5-7. DOI:10.24843/atbes. v03.i01.p02

Belakhdar G et al. 2015. Determination of some bioactive chemical constituents from Thesium humile Vahl. J Mater Environ Sci 6:2778-2783.

Butnariu M, Samfira I. 2012. Free radicals and oxidative stress. I Bioequiv Availab 4:4-6. DOI:10.4172/jbb.10000e13

Cavitch SM. 2001, Choosing Your Oil Properties of Fatty Acid. Available at: Http://users.siloverlinks.net/timer/ soapdesign. html [Date accessed: 28 Mei 2019]

Chandrasekaran M et al. 2008. Antimicrobial activity of fatty acid methyl ester of some member of Chenopodiaceae. Zeitschrift fur Naturforschung 63:331-336.

Chau CF et al. 2004. Characterization and physicochemical properties of some potential fibres derived from Averrhoa carambola. Food Nahrung 48:43-46.

Closa D, Folch-Puy E. 2004. Oxygen Free radicals and the systemic inflammatory response (Critical Review). IUBMB Life 56:185-191. DOI: 10.1080/15216540410001701642

Dasgupta P et al. 2013. Averrhoa Carambola: an updated review. International Journal of Pharma Research and Review 2:54-63.

Duengo S. 2011. Isomerisasi asam 9,12,15-oktadekantrienoat hasil isolasi minyak biji selasih (Ocimum basilicum L.). Journal Sainstek dan terapannya 6:212- 329.

Fauziati E et al. 2017. Characteristic of active compounds on extraction of fresh and dry tiwai using ethanol solvent. In: Prosiding Seminar Nasional Ke 1 Tahun 2017 Balai Riset dan Standardisasi Industri Samarinda. Samarinda: Samarinda. pp. 302-307.

Fessenden, Fessenden. 2000. Kimia Organik Edisi Ketiga Jilid Dua. Jakarta: Erlangga.

Gideon VA. 2015. GC-MS analysis of phytochemical components of Pseudoglochidion anamalayanum gamble: an endangered medicinal tree. Asian Journal of Plant Science and Research 5:36-41.

Gultom T. 2001. Individual Textbook Biokimia. Yogyakarta: Universitas Negeri Yogyakarta.

Hart $\mathrm{H}$ et al. 2003. Kimia Organik Suatu Kuliah Singkat, Terjemahan Suminar Setiati Achmadi, Edisi Kesebelas. Jakarta: Erlangga.

Hema R et al. 2011. GC/MS determination of bioactive components of Murraya koenigii.Journal of American Science 7:80-83.

Imaniar R et al. 2013. Ekstraksi dan karakterisasi senyawa bioaktif dalam daun kenikir (Cosmos sulphureus) sebagai bahan bioinsektisida alami. Indonesian Journal of Chemical Science 2:51-5 5 .

Jong SL. 2015. n-Butane and Isobutane CAS Registry Number: n-Butane: 106-97-8 Isobutane: 75-28-5. Office of the Executive Director Texas Commission On Environmental Quality.
Kanimozhi D, Bai VR. 2012. Analysis of bioactive components of ethanolic extract of Coriandrum sativum L. International Journal of Research in Pharmacy and Science 2:97-110.

Kavitha R, Uduman Mohideen AM. 2017. Identification of bioactive components and its biological activities of Abelmoschas moschatus flower extrtact-a Gc-Ms study. IOSR Journal of Applied Chemistry 10I:19-22.

Muthu N et al. 2016. Nutritional, medicinal and toxicological attributes of star-fruits (Averrhoa carambola L.): a review. Bioinformation 12:420-424.

Özçelik B et al. 2005. Antibacterial, antifungal and antiviral activities of the lipophylic extracts of Pistacia vera. Microbiol Res 160:159-164.

Padmini EA et al. 2010. Comparative analysis of chemical composition and antibacterial activities of spicata and Camellia sinennsis. Asian J Exp Biol Sci 1:772-781.

Perumalsamy $\mathrm{H}$ et al. 2015. Larvicidal activity and possible mode of action of four flavonoids and two fatty acids identified in Millettia pinnata seed toward three mosquito species. Parasites and Vectors 8:1-14.

Phaniendra A et al. 2014. Free radicals: properties, sources, targets, and their implication in various diseases. Ind J Clin Biochem 30:11-26. DOI:10.1007/s12291014-0446-0

Ping Xu D et al. 2016. Natural antioxidants in foods and medicinal plants: extraction, assessment and resources. Int J Mol Sc 18: 96-128. DOI:10.3390/ ijms18010096

Pinto MEA et al. 2016. Antifungal and antioxidant activity of fatty acid methyl esters from vegetable oils. An Acad Bras Cienc 89:1671-1681. DOI:10.1590/00013765201720160908

Ross IA. 2003. Medicinal Plants of The World. Vol.1. In: Ivan A. Ross (Eds.). Chemical constituents, traditional and modern medicinal uses. Totowa:Humana press In. pp. 455-468.

Saghir SAM et al. 2013. Star fruit (Averrhoa carambola L.): from traditional uses to pharmacological activities. Boletín Latinoamericano y del Caribe de Plantas Medicinales y Aromáticas 12:209-219.

Sanchez G et al. 2014. Avocado roots treated with salicylic acid produce phenol-2,4-bis (1,1-dimethylethyl), a compound with antifungal activity. J Plant Physiol 171:189-198. DOI:10.1016/j.jplph.2013.07.004

Satheesh Naik $\mathrm{K}$ et al, 2018. Extraction of Bio-active compounds of Eclipta Alba through GC-MS Analysis. Research Journal of Pharmaceutical, Biological and Chemical Sciences 9:297-302.

Solanki S et al. 2018. GC Analysis of In Vitro Developed Shoots of Stevia Rebaudiana Through Rapid Tissue Culture International Conference on New Horizons in Green Chemistry and Technology (ICGCT) 2018. Available at SSRN: https://ssrn.com/abstract $=3298672$ [Date accessed: 27 March 2020]

Srivastava KK, Kumar R. 2014. Stress, oxidative injury and disease. Ind J Clin Biochem 30:3-10. DOI:10.1007/ s12291-014-0441-5

Starlin T et al. 2019. Screening and GC-MS profiling of ethanolic extract of Tylophora pauciflora. Bioinformation 15: 425-429. DOI:10.6026/97320630015425

Tyagi T, Agarwal M. 2017. Phytochemical screening and GC-MS analysis of bioactive constituents in the ethanolic extract of Pistia stratiotes L. and Eichhornia crassipes (Mart.) solms. Journal of Pharmacognosy and Phytochemistry 6:195-206.

Yusa NM, Suter IK. 2014. Kajian pangan tradisional Bali dalam rangka pengembangan menjadi produk unggulan di kabupaten Gianyar. In: Prosiding Semnas Hasil Penelitian. Denpasar: Unmas press. pp. 230-236. 